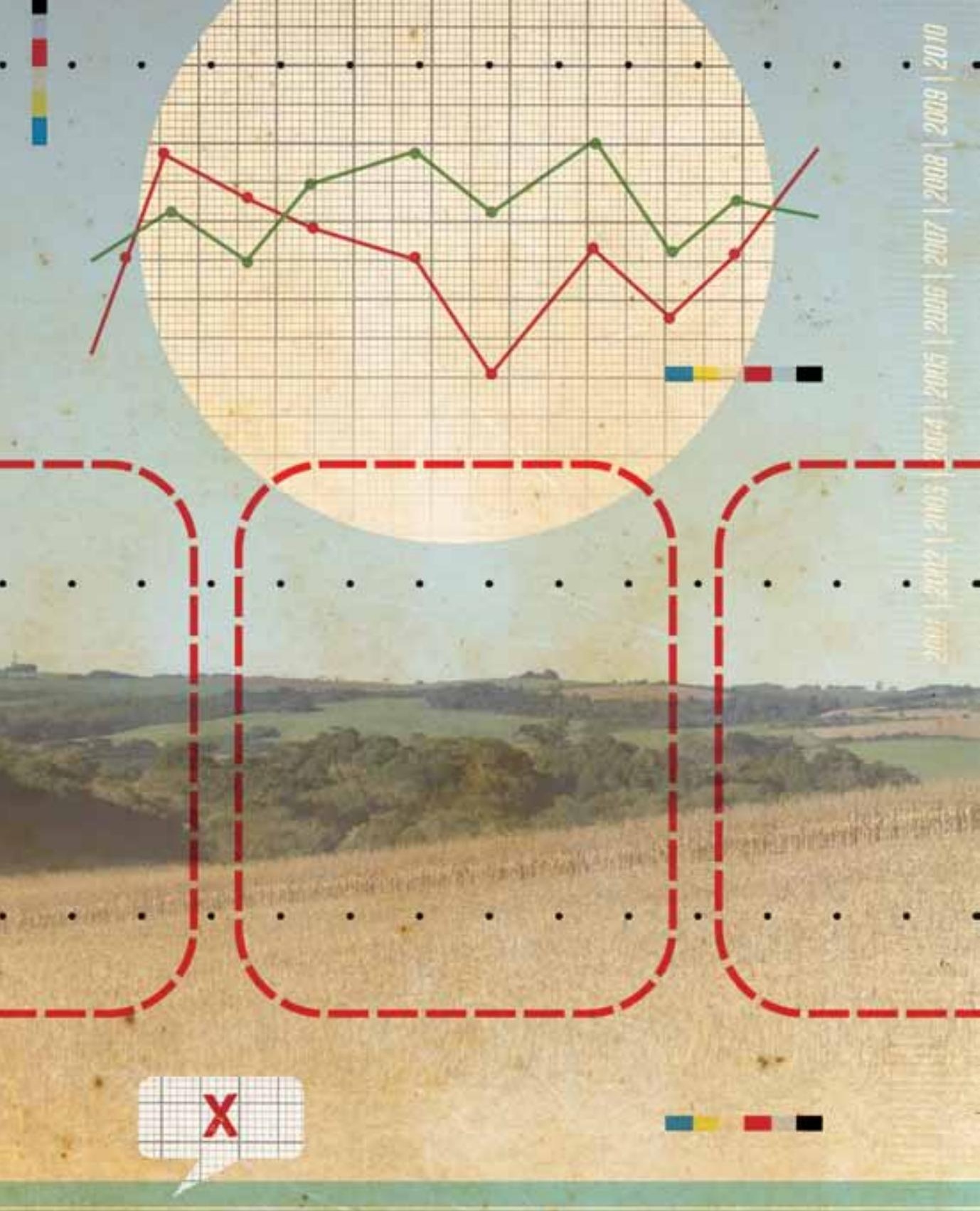




\section{As políticas de desenvolvimento territorial rural no Brasil em perspectiva - uma década de experimentações*}

\section{Territorial rural development policies in Brazil in perspective - a decade of trials}

Arilson Favareto

\begin{abstract}
Resumo
O artigo analisa as políticas brasileiras para o desenvolvimento territorial rural experimentadas durante a última década (2000-2010). 0 argumento principal pode ser sumarizado como segue. Nos anos foram verdadeiramente exitosos em termos de redução da pobreza e da desigualdade. Contudo, para alcançar uma continuidade nestes resultados positivos torna-se necessário uma nova geração de políticas em âmbito territorial. $\mathrm{O}$ artigo mostra a evolução do desenho institucional das políticas públicas para o desenvolvimento rural e aborda quais são os principais obstáculos à emergência de inovações coerentes com o novo contexto.
\end{abstract}

Palavras-chave: Desenvolvimento rural, políticas públicas, pobreza rural.

\begin{abstract}
This paper analyzes the Brazilian policies for rural territorial development during the last decade (20002010). The main argument can be summarized as following. Recent years have been really successful in terms of poverty and inequality reduction. However to achieve a continuity of this positive results is necessary a new generation of public policies at the territorial level. The paper shows the evolution of the institutional design of public policies for rural development and discusses what are the main obstacles to the rise of innovations coherent with the new context.
\end{abstract}

Key words: Rural development, public policies, rural poverty. 


\section{Introdução}

C nos anos noventa a entrada da idéia de agricultura familiar para o repertório dos movimentos sociais e dos planejadores foi a principal inovação nas políticas públicas para o rural brasileiro, na primeira década do novo milênio o mesmo ocorreu com a idéia de desenvolvimento territorial'. Não só foi criada uma Secretaria de Desenvolvimento Territorial no âmbito do Ministério do Desenvolvimento Agrário como, hoje, vários ministérios e governos estaduais operam algum tipo de "territorialização" de suas políticas. O objetivo deste artigo consiste em apresentar um balanço desta última década e avançar algumas considerações sobre quais são os principais desafios a serem superados nos próximos dez anos.

A idéia central que se pretende apresentar pode ser resumida na seguinte afirmação: não há dúvidas de que a década passada foi, sob vários aspectos, uma década vitoriosa - houve uma acentuada redução da pobreza e uma inédita redução da desigualdade, o país experimentou um crescimento econômico continuado, houve uma redução do ritmo do desmatamento, maior democratização; porém, para o caso das regiões rurais brasileiras especificamente, seria um erro imaginar que a simples continuidade da combinação entre mais recursos para a agricultura familiar e fortes políticas sociais, marcas do último período, bastará para que os resultados positivos se repitam e seus efeitos sigam sendo ampliados. Diferente disso será preciso inovar nos instrumentos de política, sob pena de ver estes resultados positivos minguarem. Quais são os nós a serem desatados e que tipo de inovações são necessárias é o que se pretende apresentar nas próximas páginas.

Para tanto, o artigo está organizado em quatro seções, além desta introdução e de uma conclusão. Na primeira seção, é apresentado de maneira tópica o cenário atual do desenvolvimento rural no Brasil, com destaque para as fortes ambigüidades que ele traz. Na segunda seção, pretende-se sustentar a afirmação de que, diante deste cenário, o país não dispõe de uma consistente estratégia de desenvolvimento rural. Na terceira seção, destacam-se especificamente os problemas de incentivos contidos no atual desenho da política brasileira de desenvolvimento territorial, com o intuito de mostrar como ela não pode, nos seus atuais contornos, ensejar uma estratégia inovadora e condizente com o atual cenário. Na quarta seção a ênfase recai especificamente sobre o tema da gestão social da política, procurando mostrar seu anacronismo.

\section{Um cenário ambíguo}

De um lado, uma das faces mais impressionantes do rural brasileiro é a vitalidade da sua agricultura comercial. E o peso deste setor na economia do país pode ser aquilatado pela proporção da sua participação nas exportações. Enquanto o setor primário respondia, no começo da década passada por pouco mais do que um décimo das exportações, este número saltou na virada da primeira para a segunda década do 
milênio para um patamar três vezes superior, em torno de um terço das exportações brasileiras.

É verdade que, em certa medida, estas exportações, puxadas pela demanda de países emergentes como a China, contribuíram decisivamente para que o Brasil escapasse dos efeitos nocivos da crise econômica internacional. Mas esta vitalidade, contudo, precisa ser vista com reservas por várias razões. Sob o ângulo econômico, esta primarização da economia traz consigo vários riscos: por exemplo, o país torna-se dependente de produtos cujos preços são determinados por fatores que fogem completamente ao controle dos agentes nacionais, as commodities; há uma especialização em torno de produtos de baixo valor agregado. Sob o ângulo social, não deve ser mero acaso a constatação de que é justamente nas regiões com mais forte presença da agricultura comercial patronal (interior de São Paulo e vastas áreas do Centro-Oeste) ou familiar (Oeste catarinense e Noroeste do Rio Grande do Sul) que não se encontra uma convergência positiva em indicadores de crescimento econômico, redução da pobreza e da desigualdade e estabilidade demográfica (Favareto e Seifer, 2011). Nestas áreas, há, sim, crescimento econômico e redução da pobreza, mas por conta da especialização e da modernização produtiva, há uma forte poupança de trabalho que se traduz em descarte de produtores ou trabalhadores, repercutindo sob a forma de aumento da desigualdade e, às vezes, de acentuada diminuição da população relativa. Sob o ângulo ambiental, deve-se registrar que os produtores agrícolas são hoje mais sensíveis ao tema e há um número expressivo de iniciativas importantes em segmentos tradicionalmente problemáticos como a cana ou a soja (Abramovay, 2010); mas também é inegável que neste setor se concentram boa parte dos problemas ambientais brasileiros como a emissão de gases estufa pela pecuária, a pressão sobre as bordas da Amazônia, o contínuo desflorestamento da Caatinga, o uso intensivo do Semi-árido, a expansão da produção de madeira emáreas deMata Atlântica.Soboângulo político, finalmente, o fortalecimento da agricultura comercial brasileira traz consigo o fortalecimento de seus representantes políticos, cuja expressão mais eloqüente é a chamada "bancada ruralista". Basta um olhar rápido sobre o posicionamento de seus membros a respeito de alguns temas recentemente discu-tidos no Congresso Nacional para confirmar que se trata de um agrupamento de cores nitidamente conservadoras.

Por outro lado, a expansão deste setor está longe de representar o único traço marcante do rural brasileiro nos últimos anos. A paisagem é bem mais diversificada e esta é a segunda característica do cenário atual: o rural brasileiro passa por um significativo processo de heterogeneização e de uma lenta diminuição das assimetrias em relação ao Brasil urbano. Os dados do último Censo (IBGE, 2011) mostram, por exemplo, que: ainda que a pobreza permaneça sendo predominantemente rural, hoje o percentual de pobres urbanos e rurais é praticamente equivalente; embora a defasagem em anos de estudo ainda seja muito grande, tem havido um aumento expressivo da escolarização entre a população rural. E no que diz respeito aos dados demográficos a heterogeneidade é ainda mais forte: as regiões de características 
rurais, no seu conjunto, praticamente se mantém estáveis em termos populacionais, concentrando em torno de $30 \%$ da população brasileira, com um leve declínio de menos de $1 \%$ em uma década, mas há um grupo expressivo de regiões de características rurais que vem perdendo participação relativa, o que denota que os efeitos positivos da última década não se manifestam de maneira homogênea no conjunto do território nacional (Favareto \& Seifer, 2010). Da mesma forma, há um crescimento da proporção de homens nestas regiões, que revela uma tendência preocupante. $O$ mesmo parece acontecer com a proporção de jovens. E, finalmente, algo particularmente importante, nos anos mais recentes há grandes avanços no que diz respeito ao reconhecimento de direitos de populações tradicionais².

Somente este quadro já seria o bastante para colocar ao menos um grão de sal na idéia de que, como nos anos recentes o país tem experimentado a ocorrência de bons indicadores, bastaria, para os próximos dez anos, fazer apenas mais do mesmo. Isto é, há uma leitura equivocada de que, no caso das regiões rurais brasileiras, a seletividade da agricultura comercial estaria sendo compensada pela ampliação dos recursos para a agricultura familiar e pelas políticas sociais. O que está ocorrendo e precisa ser melhor conhecido é um efeito muito diferente destes investimentos nas diferentes regiões. Isto é, estes investimentos públicos repercutem de maneira diferente porque são distintos os contextos e as estruturas sociais dos territórios que recebem estes recursos. Em alguns lugares eles têm significado um impulso à produção da agricultura familiar e à abertura de novas oportunidades (Quan, 2010). Mas em outros os efeitos são bem mais limitados (Favareto et al., 2010). Como se sabe, os recursos das políticas sociais são, em geral, investidos em um pequeno conjunto de bens: alimentação (com importante aumento do consumo de alimentos industrializados), remédios, materiais de construção, vestuário, material escolar e móveis e eletrodomésticos. Ora, boa parte destes bens não é produzida localmente nas regiões rurais. Com isso, os recursos entram nestas regiões, melhoram as condições de bem-estar dos beneficiários com o consumo destes bens de importância primária, e saem sob a forma de importação destes mesmos bens. O resultado é uma melhoria dos níveis de bem-estar e um aquecimento do comércio local, mas sem alteração das bases produtivas destas regiões rurais. As exceções são aquelas regiões que gozam de alguma vantagem comparativa como efeitos de proximidade com centros urbanos e aproveitam isso para dinamizar sua produção primária. Mas também aí há um limite, à medida que os preços relativos na agricultura e em outros produtos não apresentam uma tendência favorável aos agricultores no longo prazo (apesar da alta recente dos preços dos alimentos), o que torna esta atividade pouco atrativa para os mais jovens. Por esta razão é tão comum encontrar assentamentos de reforma agrária que, sem dúvida, representaram uma conquista e uma melhoria de vida expressiva para os assentados, mas que se restringem a ser local de moradia e de produção de subsistência. E por aí se pode entender também a menor vitalidade da luta pela terra num contexto de crescimento econômico: muitos dos demandantes pela reforma agrária preferem um emprego 
urbano, quando ele existe como nos anos recentes, à aridez dos acampamentos ou mesmo da vida em alguns assentamentos.

Uma última palavra precisa ser dedicada às oportunidades abertas no contexto atual. No Brasil e na América Latina como um todo, ainda são muito incipientes as iniciativas voltadas a aproveitar aquilo que a literatura chama de "novos mercados": produtos da biodiversidade ou que valorizem atributos culturais regionais, novas formas de produção de energia, turismo, pagamentos por serviços ambientais, entre outros. Mas não há dúvida de que eles representam um grande potencial. A ascensão da retórica em torno da chamada economia verde bem o demonstra (Conservação Internacional, 2011; United Nations, 2012).

É muito provável que, no próximo período, as vinculações entre a agenda do desenvolvimento rural e a agenda do meio-ambiente se tornem ainda mais próximas. As oportunidades abertas pelo novo contexto podem ser usadas para propiciar melhores possibilidades de inserção dos agricultores mais pobres, ou podem repercutir negativamente sobre eles (como bem o demonstram as grandes obras e energia nos tempos atuais). O certo é que este tema não pode permanecer à parte da agenda do desenvolvimento rural como hoje acontece.

Neste contexto, a pergunta que precisa ser feita é: o Brasil tem uma estratégia de desenvolvimento rural compatível com os elementos trazidos pelo cenário aqui brevemente esboçado?

\section{O Brasil rural não tem uma estratégia de desenvolvimento}

No final dos anos noventa o NEAD publicou um volume organizado por José Eli da Veiga que trazia como título "O Brasil rural precisa de uma estratégia de desenvolvimento" (Veiga et al, 1998). Quatorze anos depois, a afirmação continua válida. Não se trata de reivindicar que o país faça uma opção pela agricultura familiar ou pela agricultura patronal. Hoje há uma forte e competitiva agricultura comercial assentada sobre ambos os segmentos, e tudo indica que isto continuará assim pelos próximos anos ${ }^{3}$. O fundamental é uma estratégia que sinalize ao conjunto de agentes públicos e privados, um pequeno conjunto de temas ou questões para a qual se deveria buscar convergir esforços e investimentos. Esta é a questão chave: sem um acordo em torno desta agenda, continuará a prevalecer a pulverização e a fragmentação de iniciativas e seus efeitos heterogêneos, como se mostrou acima.

À luz do que foi dito sobre o cenário atual, para que se tenha uma estratégia de desenvolvimento rural, mais do que de desenvolvimento agrícola, seria preciso uma agenda em torno de, pelo menos, os seguintes pontos:

\section{Diversificação e dinamização das economias interioranas}

A forte ampliação dos recursos circulando nas regiões rurais, em grande medida por conta da municipalização de políticas públicas e do fortalecimento das políticas sociais, 
é algo que precisa ser melhor aproveitado para diminuir a dependência destas fontes externas. Para isso, é preciso diversificar estas economias locais (não se trata somente de diversificar a produção agrícola, mas de diversificar os serviços e a transformação de bens primários). Somente assim poderão ser criadas outras oportunidades mais atrativas aos mais jovens e à população com maior escolaridade. Isto permitiria elevar salários, ampliar postos de trabalho, diminuir a dependência externa, conter a fuga de pessoas. E para diversificar essas economias locais é necessário aproximar a gestão das políticas sociais de outras políticas produtivas, algo que o atual desenho do Brasil Sem Miséria ou mesmo as políticas do MDA não contemplam.

\section{Um pacto pela paridade entre regiōes rurais e urbanas}

Hoje não há uma diferenciação nas políticas urbanas, de saúde ou de educação para regiões rurais ou urbanas. Mas a forte assimetria que existe entre estes dois universos precisa ser tratada afirmativamente. Seria preciso, por um lado, estabelecer metas para que, no intervalo de uma geração, um habitante de regiões interioranas, de características rurais, tivesse garantido o acesso à mesma cesta de serviços de que dispõe um habitante de regiões urbanas, metropolitanas. Claro que determinados serviços só podem ser oferecidos nos grandes centros por conta de custos e escala, como clínicas especializadas ou coisas do tipo. Mas em alguns indicadores básicos (saúde básica e de média complexidade, ensino fundamental e médio, expectativa de vida, mortalidade infantil, entre outros) seria necessário um plano específico, já que há uma tendência à concentração de investimentos nos grandes centros. Vários ministérios, como o das Cidades, admitem que não possuem habilidades para elaborar estratégias específicas para as regiões interioranas e que, ali, não se pode ter o mesmo tipo de estratégia usada nos grandes centros urbanos. E não se trata de fazer proliferar experiências como a chamada "Educação do Campo". Isto é importante em certos contextos, obviamente, mas, mais importante, é aproximar a rede pública de educação das escolas técnicas e da rede de universidades que se criou nas áreas interioranas por ocasião da recente política de expansão do ensino superior.

\section{O Brasil rural e a Economia verde}

Para que a chamada Economia verde não seja apenas um discurso ou uma oportunidade de lucro para o setor empresarial, é fundamental que o Brasil rural incorpore afirmativamente a variável ambiental em uma estratégia de desenvolvimento. Isto passa pela pesquisa sobre sistemas de produção e técnicas agrícolas mais adequadas aos requisitos da conservação ambiental, mas também pela introdução de novos produtos e serviços que são, muitas vezes, bloqueados por uma visão religiosa de que o trabalho na terra só é legítimo quando voltado para a produção de alimentos. É claro que a produção de alimentos ainda é e será por um bom tempo a principal vocação do uso de terras, mas é inegável que em muitas regiões brasileiras 
isto pode não ser um imperativo, ao contrário até, em vários locais as oportunidades de obtenção de renda e de ampliação de oportunidades passa por outros usos sociais dos recursos naturais. Isso implica em mudanças culturais, mas também institucionais e na introdução de inovações ou na organização de novos mercados.

Todos estes temas estão ausentes ou excessivamente diluídos nas diretrizes que saíram da última Conferência Nacional de Desenvolvimento Rural Sustentável (CNDRSS, 2008). O documento final espelha um conjunto de diretrizes que são amplas o suficiente para abarcar as reivindicações do diversificado conjunto de segmentos sociais que representam os pobres do campo, mas demasiadamente frágeis para dar corpo a uma verdadeira estratégia, que comporte um conjunto de prioridades partilhadas pelos agentes sociais públicos e privados, ou mesmo para dar conta dos desafios que emergem de um contexto como aquele esboçado na seção anterior. Da mesma forma, o atual desenho da política de desenvolvimento territorial não põe em funcionamento um conjunto de incentivos capazes de ordenar os instrumentos de política pública e os investimentos numa tal direção. À análise deste desenho e destes incentivos é dedicada a próxima seção.

\section{Problemas de planejamento - que incentivos para que estratégia de desenvolvimento rural?}

Esta terceira seção do artigo descreve a evolução das tentativas de pôr em prática a abordagem territorial do desenvolvimento rural ao longo da primeira década deste século e traça um balanço sobre os avanços e sobre os impasses ainda a serem superados. Da ampliação do Pronaf-infraestrutura municipal para a escala territorial até o Territórios da Cidadania e ao Brasil Sem Miséria, passando pelo Territórios de Identidade, a experiência brasileira é tomada como um processo de aprendizagem institucional ${ }^{4}$.

Ainda nos ultimo período do Governo Fernando Henrique Cardoso foram introduzidas mudanças que tentavam dialogar com resultados das pesquisas e estudos sobre o rural brasileiro, em geral, e sobre o Pronaf, em particular. A mais significativa delas foi a destinação de parte dos recursos do Pronaf/Infraestrutura para projetos com caráter intermunicipal, tentando, assim, introduzir os primeiros componentes de uma política de desenvolvimento territorial, que seria fortemente ampliada no inicio do Governo Lula, com a criação de uma secretaria especifica destinada a gerir esta linha do Pronaf: a Secretaria de Desenvolvimento Territorial do Ministério do Desenvolvimento Agrário.

Com a criação da SDT e a autonomização da vertente infraestrutura do Pronaf, agora sob sua jurisdição, ocorreram dois movimentos. Por um lado, todos os investimentos a título de apoio a infraestrutura passaram a ser feitos em agregados de municípios. Junto disso, modificou-se também o marco para a participação social na gestão do programa. Em vez de conselhos municipais, passa-se a estimular e exigir a criação de Colegiados Territoriais. 
Duas questões podem ser elencadas a título de avaliação do funcionamento destas articulações para o desenvolvimento territorial, a partir das quais se poderia avaliar em que medida elas incorporaram as avaliações apontadas nos estudos sobre desenvolvimento rural da virada da década: a) os colegiados e a articulação que eles representam envolveram estritamente o público-alvo do MDA, ou eles lograram envolver as forças sociais mais influentes dos territórios para além de parte da agricultura familiar e do poder público local?; e b) os colegiados conseguiram construir uma agenda mais ampla do que a mera gestão dos recursos e projetos vinculados ao Proinf, ou foram mais uma vez um espaço de fiscalização e controle da aplicação de recursos de um programa? Estas perguntas foram perseguidas em levantamento do próprio MDA e sistematizado em relatório elaborado por Dias \& Favareto (2007), cujos principais pontos são reproduzidos sumariamente a seguir.

No que diz respeito à análise da composição dos colegiados viu-se claramente a forte presença das organizações de representação da agricultura familiar, principalmente através de seus sindicatos, mas também por meio dos movimentos de trabalhadores rurais sem-terra e, em menor número, de movimentos de mulheres trabalhadoras rurais. Mais que isso, observou-se que, com nuanças regionais, as diferentes correntes políticas dos movimentos sociais reconheciam e participavam destas articulações, o que era altamente positivo. Porém, observações de campo sugeriam que os movimentos e organizações presentes representavam os segmentos intermediários da agricultura familiar e demais populações rurais. Para se falar em representação efetiva da agricultura familiar, em sua heterogeneidade, seria preciso ainda criar formas e mecanismos de envolver, tanto os segmentos mais precarizados desta forma social de produção, como aqueles mais capitalizados e inseridos em mercados.

A primeira ressalva negativa diz respeito aos segmentos que conformam o público prioritário do MDA, mas que não alcançam a mesma visibilidade dos agricultores familiares e trabalhadores rurais sem-terra, caso específico dos indígenas e quilombolas. Mesmo nas regiões onde estes segmentos têm expressão numérica eles estavam ausentes das articulações territoriais e, por decorrência, poucas vezes eram alcançados pelos principais investimentos feitos ali. A segunda ressalva negativa dizia respeito à ausência de organizações de jovens agricultores ou da participação individual de agricultores com estas características nos colegiados territoriais. Isto é particularmente importante quando se pensa que a principal missão destas instâncias é projetar uma visão de futuro para as regiões rurais e instrumentos capazes de levar a ela. Sem dar voz às expectativas deste segmento que responderá pela ocupação dos principais postos de direção das organizações ou pela chefia dos estabelecimentos agrícolas, restringe-se brutalmente tanto a leitura dos anseios da população local como a capacidade de eco das ações em curso perante as gerações mais novas.

Já quando se trata de saber se esses colegiados conseguiam envolver as forças sociais mais influentes dos territórios a resposta foi francamente negativa. $O$ número de 
organizações representativas do setor patronal ou de outros setores da economia para além do agro era, no meio da década, absolutamente inexpressivo. $\mathrm{E}$ a necessidade de se alcançar tais setores não é mero elogio à diversidade. Ela se faz necessária por duas razões complementares. Primeiro, com a tendência histórica de declínio da renda agrícola e da demanda por mão-de-obra na agricultura, o futuro das regiões rurais passa necessariamente pela diversificação de seu tecido social e econômico. Se é verdade que a agricultura familiar é base fundamental para isso e deve ser priorizada nos investimentos públicos, é igualmente verdade que somente através dela é impossível garantir horizonte estratégico para a dinamização da vida econômica e social de qualquer território. Um bom exemplo disso é o contraste entre regiões como o Noroeste gaúcho ou o Oeste Catarinense e o Vale do Itajaí. Em ambas as situações são regiões onde predomina a agricultura familiar e com um grau razoável de consolidação. No entanto, no Noroeste gaúcho e no Oeste Catarinense ocorre hoje uma crise demográfica e uma situação de precariedade na manifestação dos indicadores de desenvolvimento, enquanto no Vale do Itajaí ou na região da Serra Gaúcha, assiste-se a situação inversa. Uma das razões desta diferença está justamente no grau de diversificação da economia e do tecido social local. A segunda razão diz respeito às próprias condições de êxito da política de desenvolvimento territorial: sem uma ampliação dos interesses e dos agentes envolvidos o alcance restringe-se a um único setor, tornando inclusive inócua a associação do adjetivo 'territorial' a tais investimentos.

Pode-se dizer, portanto, que com os colegiados territoriais houve duas mudanças em relação ao período anterior das políticas para o desenvolvimento rural no Brasil: a) a escala das ações passou do âmbito municipal para o intermunicipal, ainda que muitas vezes a lógica dos investimentos e dos projetos permaneça municipalizada; b) houve um maior envolvimento das organizações da sociedade civil numa política que, até então, tinha preponderância do Executivo Municipal. No entanto, a outra dimensão contida na abordagem territorial do desenvolvimento, a intersetorialidade, praticamente inexiste nos colegiados territoriais estudados. E isto, repita-se, limita enormemente o alcance da política, pois as iniciativas apoiadas acabam se circunscrevendo, no mais das vezes, ao apoio a atividades já tradicionais entre os agricultores.

Quando se trata de saber se os colegiados teriam uma agenda mais ampla do que a mera gestão dos recursos de um programa, novamente aqui a resposta não foi tão positiva. A larga maioria dos casos mostrou que a dinâmica e a agenda dos colegiados territoriais era pautada pela elaboração e negociação dos projetos do Proinf, substituto do Pronaf/Infraestrutura. E mesmo a elaboração dos Planos Territoriais de Desenvolvimento Rural não era, ali, o principal item. Até nos territórios onde isso ocorria, a fragilidade da composição dos colegiados e a inexistência de articulação com outras iniciativas afins revelavam um sério risco de que uma eventual descontinuidade na política de apoio por parte do governo federal levasse a uma drástica paralisia destes organismos. Isto era reforçado também pelo baixíssimo 
número de colegiados que procederam a alguma forma de institucionalização, com a elaboração de regimentos ou instrumentos afins.

Como foi destacado anteriormente, pode-se atribuir tal dificuldade ao caráter embrionário desta iniciativa. No entanto, é razoável supor que sem uma mudança nos mecanismos e nas formas de incentivo aos agentes locais dificilmente se conseguiria superar os limites apontados. Tal suposição deriva de que as regras atuais estão bem orientadas para ampliar a participação da sociedade civil, mas não há nada que sinalize verdadeiramente na direção de influenciar de maneira consistente e decisiva as dinâmicas territoriais. O que há é a expectativa, já presente desde a experiência dos CMDR, de que, com maior participação, melhor a eficiência na alocação dos recursos. Esta expectativa, como já foi dito, tem sido fortemente contrariada em um amplo rol de estudos que se dedicaram a entender a relação entre participação e desenvolvimento ${ }^{5}$. Daí a constatação de que seria preciso, urgentemente, passar em revisão as regras das políticas territoriais e aprimorar seus instrumentos.

Vale dizer que este não é um problema restrito à política da SDT/MDA ou mesmo do governo federal brasileiro, como bem o demonstra o estudo de Veiga (2007) sobre os Conselhos Regionais de Desenvolvimento no Rio Grande do Sul, ou o trabalho comparativo de Coelho et al. $(2007,2008)$ sobre o Consad e o Comitê de Gestão de Recursos Hídricos do Vale do Ribeira paulista; ou ainda os vários estudos levados adiante em diferentes países da América Latina no âmbito do Projeto Movimentos Sociais, Governança Ambiental e Desenvolvimento Territorial Rural, promovido pelo Rimisp. Mesmo para a realidade européia, que inspira fortemente a iniciativa brasileira, o entusiasmo inicial com ações como aquelas previstas no Programa Leader, vêm gradativamente dando lugar a avaliações que enfatizam uma espécie de efeitos não previstos dos processos de participação, como se pode constatar, por exemplo, nos trabalhos de Ray $(2000,2002)$.

Em síntese, os dados e análises disponíveis no meio da década sugeriam que os colegiados territoriais conseguiram imprimir algumas mudanças em relação ao que os espaços participativos voltados para a gestão das políticas de desenvolvimento rural haviam conseguido nos anos noventa. Quando se olha para o que apontavam vários estudos que tiveram os Conselhos Municipais de Desenvolvimento Rural como objeto, vê-se que pelo menos dois limites ali apontados foram superados: a) aquilo que alguns chamavam por "prefeiturização" dos CMDR foi, se não eliminado, ao menos minimizado; b) a escala de abrangência das articulações (não dos investimentos, que fique claro) deixou de se dar nos limites dos municípios para alcançar uma escala intermunicipal.

No entanto, ao menos outros dois aspectos destacados neste mesmo rol de estudos continuam ausentes das preocupações e das ações práticas destes colegiados: a) a idéia de territorialização das iniciativas envolve bem mais do que a ampliação da escala geográfica e diz respeito mesmo ao reconhecimento das dinâmicas locais e da diversidade de atores que compõem as regiões rurais, sobre o quê há pouco 
entendimento e diálogo nas articulações em curso; e b) a estrutura de governança posta em prática nestes colegiados estava longe de sinalizar um sistema de incentivos capaz de engendrar ações consistentes, eficientes e com horizonte estratégico para estas mesmas regiões rurais.

Por tudo isso é possível dizer que o grande mérito destes colegiados está em ter aprofundado as possibilidades de controle social das políticas de desenvolvimento rural e em ter disseminado a retórica correspondente à abordagem territorial do desenvolvimento rural. Mas é forçoso reconhecer que o caminho para que eles possam se impor como novas instituições para o desenvolvimento rural ainda é longo. Para tanto, seria preciso proceder a uma série de ajustes estruturais nas diretrizes e na operacionalização da política de desenvolvimento territorial. Em 2008 deu-se mais um passo, com a criação do Territórios da Cidadania e a expectativa de uma verdadeira integração para além dos limites de um ministério.

Apesar do seu caráter recente, cabe pontuar ao menos alguns dos seus principais desafios. Congregando ações de dezenove ministérios e com expressivo montante de recursos sob coordenação da Casa Civil do Governo Federal, o Territórios da Cidadania foi apresentado como uma tentativa de integrar e dar coesão a um conjunto de ações, antes dispersas em diversas estruturas do Poder Executivo. Por isso, para muitos o programa passou a ser visto como uma espécie de complemento do Programa de Aceleração do Crescimento, principal programa brasileiro, e sinal de que, finalmente, o Brasil rural passava a ser tomado como prioridade. Porém, em três anos de existência este programa se desidratou. Os territórios continuam sendo vistos como um repositório de investimentos. Não mais que isso. As ações vinham sendo selecionadas pelo Poder Executivo dentre os investimentos que já estavam planejados nos diferentes programas antes dispersos e ofertados aos territórios, a quem caberia somente definir prioridades dentro desse cardápio. Sob esse prisma, o Territórios da Cidadania foi apenas mais uma inovação parcial. Inovação importante, porque abria a possibilidade inédita de que se reconheça o Brasil rural, o Brasil interiorano, o Brasil profundo como um espaço de investimentos tendo por foco os segmentos mais precarizados. Mas inovação parcial porque reproduziu uma dicotomia: para o Brasil dinâmico, a aceleração do crescimento, e para o Brasil rural ampliação da cidadania dos mais pobres.

Esta mesma dicotomia se fez presente no lançamento do programa Brasil Sem Miséria, em 2011, voltado à erradicação da pobreza extrema no Brasil: ali havia uma estratégia para o Brasil urbano, baseada em mapeamento de oportunidades associada às bolsas, e uma estratégia para o Brasil rural, equivocadamente baseada na repetição de instrumentos de eficácia limitada como a distribuição de sementes.

Para uma incorporação a contento da chamada abordagem territorial, tal como ensina a literatura especializada e a experiência internacional, seria preciso no mínimo superar a dicotomia entre redução da pobreza e dinamização econômica. Obras de infra-estrutura e políticas sociais ou focalizadas são condições básicas, mas estão longe 
de ser o bastante para promover o desenvolvimento territorial. Como explicar, por exemplo, a ausência no âmbito do Programa Territórios da Cidadania dos Ministérios do Turismo, da Indústria e Comércio ou da Ciência e Tecnologia? Seria possível promover o desenvolvimento regional sem ações que estão na alçada desses ministérios? O mais importante dilema permanece sem solução e, pior, sem portadores sociais capazes de equacioná-lo: como não confinar as regiões interioranas ao eterno delivery de políticas públicas.

Em resumo, há quatro campos em que o desenho da política precisaria dispor outros tipos de incentivos. São eles:

\section{Estabelecimento de metas:}

Os investimentos feitos atualmente pela política de desenvolvimento territorial se justificam somente pela execução dos recursos e pelo público beneficiário. Mas não há planejamento em torno de metas a serem atingidas ou de indicadores a serem impactados. Seria preciso o desenho de metas progressivas e, a partir disso, disponibilizar recursos para investimentos capazes de alcançar estas metas. Isto vale para diversificação econômica, para melhoria de renda, para educação, e assim sucessivamente.

\section{A diversificação dos instrumentos e uma tipologia do Brasil rural:}

Diante da diversidade do Brasil rural, uma política de desenvolvimento territorial não pode se basear numa única modalidade de investimentos. Diferente disso, é preciso ter uma tipologia de territórios rurais. Em alguns casos, trata-se de disponibilizar recursos para investimentos e não para financiar reuniões ou a elaboração de diagnósticos, pois eles já existem. Em outros locais, o nível de articulação e de gestão é tão precário que não vale a pena fazer pesados investimentos sem que se saiba onde é melhor investir, com quem se pode contar. Nestes casos, os investimentos devem se dar na formação de capital social e institucional, e só depois em investimentos produtivos. Da mesma forma, quando se fala em investimentos produtivos, a política deveria incentivar empreendimentos inovadores ou com maior capacidade de geração de renda. Nem sempre o simples atendimento a demandas é a melhor forma de promover a dinamização ou a reestruturação produtiva de certas regiões. E em muitos casos, esta é a necessidade.

\section{Dos Planos ờs Estratégias de desenvolvimento territorial}

Os Planos de Desenvolvimento Territorial Sustentável são hoje peças burocráticas que servem para justificar a aplicação de recursos. Na maior parte dos casos estão longe de materializar um horizonte de médio prazo e os caminhos para construí-lo. Seria preciso aportar recursos (não só financeiros, mas sobretudo humanos) para 
fazer destes planos verdadeiras estratégias de organização do território sobre outras bases. Deles deveriam fazer parte outros recursos e outros agentes além daqueles tradicionalmente mobilizados. Sem isso os investimentos permanecerão restritos ao emergencial e ao imediato.

\section{De recursos a fundo perdido à seleção de projetos inovadores}

Hoje os territórios contam com recursos garantidos, independente da qualidade dos projetos. Em vez disso, se deveria premiar os melhores projetos, aqueles que apresentam maior complementaridade com outras iniciativas, os que são mais inovadores e mais aderentes aos desafios dos territórios rurais. Pode-se argumentar que isso reforçaria as desigualdades à medida que os territórios mais organizados tendem a elaborar os melhores projetos. Mas isto poderia ser contornado com a constituição de diferentes fundos - por exemplo, um fundo para os territórios com organização mais avançada e financiando projetos mais inovadores, e outro para os territórios em estágio de articulação e financiando atividades mais básicas. $\mathrm{O}$ importante seria sinalizar aos territórios o que é um bom projeto de desenvolvimento territorial e, por aí, reforçar o aprendizado.

\section{A agenda da gestão social envelheceu}

O atual desenho da política de desenvolvimento territorial, como se viu na seção anterior, privilegia claramente um aspecto: a gestão social da política. Há uma clara aposta de que a criação de espaços participativos levaria a uma maior eficiência nos investimentos. E isso ocorreria por duas razões: ao haver maior participação, haveria maior controle social sobre os investimentos, aumentando sua eficácia; e com esta participação as políticas alcançariam as verdadeiras prioridades, já que as pessoas que vivem as necessidades de investimentos sinalizariam onde seria melhor fazê-los. Estas duas razões estão presentes em todas as iniciativas que tomam o "empoderamento" dos atores sociais como critério de sucesso (Coelho \& Favareto, 2011).

Como já foi dito, não há dúvida de que este movimento levou a uma maior democratização da política (maior transparência, sobretudo), principalmente quando comparada com a década anterior, quando os investimentos ficavam restritos à alçada das prefeituras municipais, que, no interior do Brasil, são bastante deficientes em sua capacidade administrativa e de descentralização de poder à sociedade. Mas por outro lado, isto está longe de ser o suficiente para uma verdadeira eficiência dos investimentos. Para isso, se teria que avaliar não somente se os investimentos feitos atenderam às demandas apresentadas nos conselhos, e sim se elas tiveram capacidade de incidir positivamente sobre as dinâmicas territoriais. Isto é o que se esperava com a ampliação dos recursos do Pronaf/infraestrutura em direção a uma política de desenvolvimento territorial. E aí, as avaliações disponíveis não são muito favoráveis. 
Não se trata de dizer que a gestão social das políticas públicas é um desafio superado, e sim que os desafios na gestão social das políticas públicas tornaram a agenda que hoje inspira essas formas de participação social, algo envelhecido. Em outras palavras, os instrumentos de participação social hoje são os mesmos desenhados há duas décadas. E, no entanto, já há aprendizagem com as experiências que permitiria refinar e aprimorar estes mesmos instrumentos.

Uma primeira inovação que se poderia introduzir nas formas de gestão social das políticas públicas diz respeito aos atores mobilizados. Hoje participam, predominantemente, gestores públicos e representantes das forças sociais organizadas (sindicatos, associações). Em geral, os mais pobres não participam sequer das organizações de agricultores. Além disso, para se promover o desenvolvimento territorial não se pode mobilizar somente os atores sociais ligados ao agro. Claro que os segmentos mais pobres não têm as mesmas habilidades que os setores empresariais para participar em situação de igualdade em uma reunião ou fórum. Isso leva à segunda inovação necessária.

A segunda inovação diz respeito às formas de participação social. Não é somente fazendo duas reuniões ao ano para discutir onde serão aplicados os recursos daquele período que se pode promovê-la. Diferente disso, pode-se lançar mão de consultas voltadas a segmentos específicos. $\mathrm{E}$, igualmente, pode-se ter momentos mais amplos a exemplo do que acontece com as Conferências de Saúde.

A terceira inovação diz respeito à cumulatividade e alcance das definições. A participação social deveria ser cumulativa. Isto é, os Planos discutidos não deveriam ser meras peças burocráticas, mas sim diretrizes como os Planos Diretores de municípios, que são revistos e atualizados a cada período.

Tudo isso contribuiria para aprimorar a tecnologia da participação social, tornando a política mais aderente às necessidades e à heterogeneidade do Brasil rural. $\mathrm{E}$, ao mesmo tempo, contribuiria também para libertá-la do risco de restringir-se somente às forças sociais organizadas.

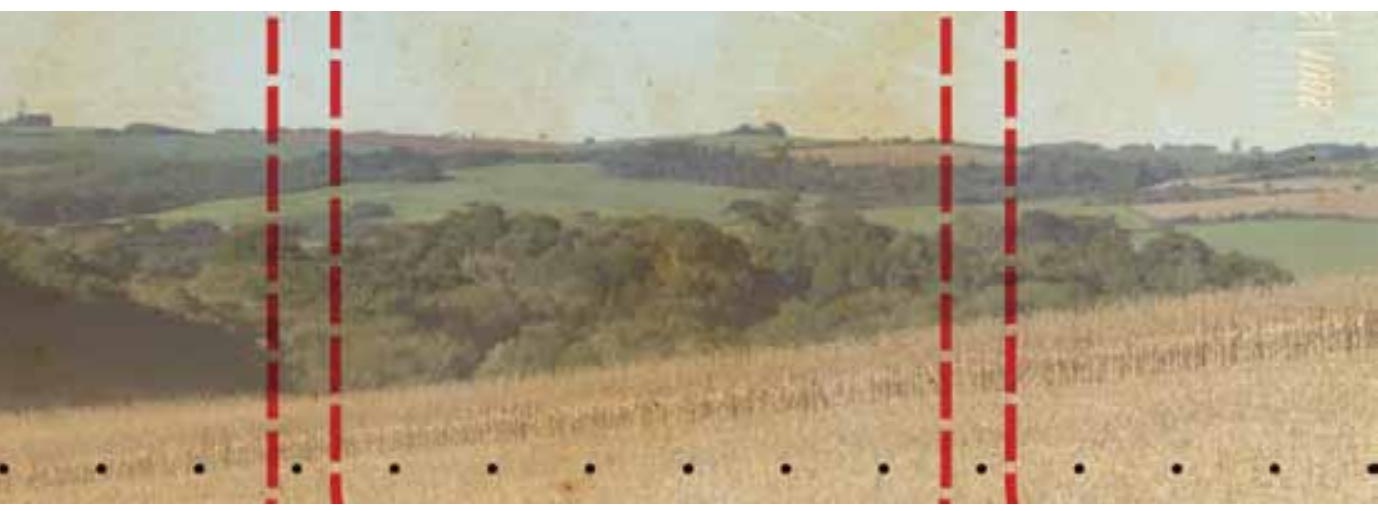




\section{Conclusão}

O que se tentou demonstrar nas páginas anteriores é uma espécie de "movimento das contradições" na experimentação da idéia de desenvolvimento territorial. Viu-se que o processo de mudança nessa direção tem sido incremental, com ajustes periféricos, é verdade, mas que não podem ser desprezados. Hoje a retórica do desenvolvimento territorial abrange um conjunto de agentes, ainda que com compreensões variadas e tantas vezes incompletas. Mas criou-se um campo cognitivo a partir do qual se pode tentar tornar esses avanços mais rápidos e consistentes.

Para isso, no entanto, não basta fazer mais do mesmo nos anos que virão. É preciso identificar alguns dos principais desafios nessa transição de paradigma e promover a atualização dos dispositivos institucionais numa direção coerente. Aqui se tentou oferecer uma leitura de que desafios seriam esses, e exemplificar mudanças que poderiam ser fomentadas. Se são estes ou não os desafios e propostas, isto é algo que cabe ao debate científico e social resolver. $O$ fundamental é que o futuro das regiões rurais possa ser pensado em novas bases de relação entre sociedade, natureza e economia. A abordagem territorial do desenvolvimento abre uma porta interessante para transformar o ideal normativo contido na idéia de desenvolvimento sustentável algo operativo por meio de políticas públicas. Completar a transição iniciada uma década atrás com a adoção desta retórica é a tarefa sobre a qual deveriam se concentrar todos os esforços no próximo período.

Há, contudo, um desafio que vem bloqueando o aperfeiçoamento da política de desenvolvimento territorial desde que ela foi introduzida. E esta dificuldade não se restringe ao Brasil, mas se repete em outros países latinoamericanos. A ascensão da idéia de agricultura familiar, por exemplo, teve um portador claro: os movimentos sociais da agricultura familiar em aliança com um pensamento científico e com gestores de políticas que viram neste público um segmento prioritário numa estratégia de desenvolvimento rural. Mas a ascensão da abordagem territorial do desenvolvimento traz um complicador: quem são os portadores dos interesses mobilizados nesta abordagem? Por definição, não se trata de um único portador, nem de um único segmento. Mais ainda, uma verdadeira estratégia territorial, por vezes teria que contrariar os interesses do agro e favorecer uma maior diversificação das economias locais. Trata-se, portanto, de interesses mais difusos e, em alguma medida, conflitantes com os daqueles que hoje se beneficiam com o viés dos investimentos feitos e que sustentam a própria existência do Ministério do Desenvolvimento Agrário. Aí reside um dilema que pode limitar a mudança e o aperfeiçoamento da política brasileira para o desenvolvimento rural. 


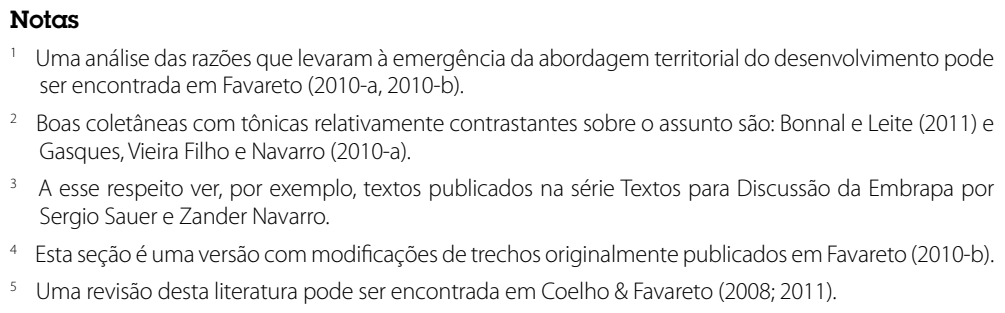

\section{Referências Bibliográficas}

ABRAMOVAY, Ricardo (2010). A political-cultural approach to the biofuels. Relatório de Pesquisa. Consultado em www.abramovay.pro.br

BONNAL, Philippe e LEITE, Sergio Pereira - orgs. (2011). Análise comparada de políticas agrícolas - uma agenda em transformação. Rio de Janeiro: Mauad Ed.

CNDRSS (2008). Conferência Nacional de Desenvolvimento Rural Sustentável. Consultado em www.mda.gov.br

COELHO, Vera Schattan Pereira et al. (2007). Foros participativos y desarrollo territorial en el Valle de Ribeira (Brasil). In: BENGOA, José. (Org.). Territorios rurales - movimientos sociales y desarrollo territorial rural en América Latina. 1 ed. Santiago de Chile: Catalonia, 2007, v. , p. 459481

COELHO, Vera Schattan Pereira e FAVARETO, Arilson (2011). Participatory governance and development - in search of a causal nexus. Geography Compass, v. 5, p. 641-654, 2011

COELHO, Vera Schattan Pereira e FAVARETO, Arilson (2008) Dilemas da participação e desenvolvimento territorial. In: DAGNINO, Evelina; Luciana Tatagiba. (Org.). Democracia, sociedade civil e participação. 1 ed. Chapecó: Argos, , v. , p. 97-126

CONSERVAÇÃO INTERNACIONAL (2011). Política ambiental - Economia verde. Volume 18.

DIAS, Marcelo M. e FAVARETO, Arilson (2007). Um retrato preliminar dos colegiados territoriais no Brasil - novas instituições para o desenvolvimento rural ? Relatório de Pesquisa. Brasília: SDT/ MDA.

FAVARETO, Arilson (2010-a). A abordagem territorial do desenvolvimento rural - mudança institucional ou inovação por adição ?. Estudos Avançados (USP), v. 24, p. 299-319, 2010.

FAVARETO, Arilson (2010-b). Tendências contemporâneas dos estudos e políticas de desenvolvimento territorial. In: BACELAR, Tania. (Org.). Políticas de desenvolvimento territorial rural no Brasiil - avanços e desafios. Brasília: IICA, 2010, v. 12, p. 15-46.

FAVARETO, Arilson e SEIFER, Paulo (2011). Informe latinoamericano sobre crescimento com inclusão social. Relatório de Pesquisa. Santiago do Chile: Rimisp.

FAVARETO, Arilson et al. (2010). Desenvolvimento territorial em uma região do Semi-árido do Nordeste do Brasil - para além das transferências de renda. Série Documentos de Trabajo n. 83. Santiago de Chile: Rimisp.

IBGE (2011). Resultados preliminares do Censo Demográfico de 2010. Consultado em www. ibge,gov.br

QUAN, Julian (2010). Territorial diversity and inclusive growth - development dymanics in the Jiquiriça Valley in Northeast Brazil. Série Documentos de Trabajo n. 72. Santiago de Chile: Rimisp. 
RAY, Cristopher (2000). The EU Leader Programme - rural development laboratory. In. Sociologia Ruralis. Vol. 40, n. 2, April 2000.

RAY, Cristopher (2002). A mode of production for fragile rural economies - the territorial accumulation of forms of capital. Journal of Rural Studies. Vol. 18. P. 225-231.

UNITED NATIONS (2012). United Nations Conference on Sustainable Development. Draft Zero. Consultado em http://www.uncsd2012.org/rio20/index.html

VEIGA, José Eli (2007). Vicisitudes de la gobernanza ciudadana - Los Consejos Regionales Gauchos (Coredes). In: BENGOA, Jose - org. Territorios rurales: movimientos sociales y desarrollo territorial rural em America Latina. Santiago de Chile: Catalonia.

VEIGA, José Eli et al. (1998). O Brasil rural precisa de uma estratégia de desenvolvimento. Série Textos para Discussão. Vol. 1. Brasília: NEAD.

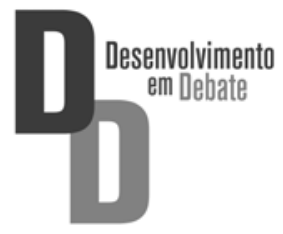

